\title{
Comparison between gingival pyogenic granuloma and peripheral giant cell granuloma by immunohistochemical detection of CD34 and alpha smooth muscle actin
}

\author{
Aween Auda Ablahad, ameera Kamal Khaleel, ${ }^{* b}$ and Jasim Almahana ${ }^{b}$
}

\author{
ainistry of Health, Erbil, Kurdistan Region, Iraq \\ bepartment of Dentistry, Al-Hussein University College, Karbala, Iraq. \\ *Correspondence to Ameera Kamal Khaleel (email: amera1kam@yahoo.com) \\ (Submitted: 27 November 2018 - Revised version received: 16 December 2018 - Accepted: 12 March 2019 - Published online: 26 June 2019)
}

\begin{abstract}
Objectives The aim of this research was to study the clinical and the immunohistochemical expressions of CD34 and alpha smooth muscle actin (a-SMA) for gingival pyogenic granuloma in comparison with peripheral giant cell granuloma.

Methods Formalin fixed, paraffin-embedded biopsy specimens of 48 gingival pyogenic granuloma and 39 peripheral giant cell granuloma were used in the study. Immunohistochemical analysis for CD34 and a-SMA were studied in pyogenic granuloma (PG), peripheral giant cell granuloma (PGCG).

Results The mean numbers of the CD34 positive microvessels in PGs and PGCGs were $32.58 \pm 17.778$ and $22.4 \pm 11.208$, respectively. Statistical analysis showed a highly significant difference present between them $(P<0.01)$. The mean numbers of blood vessels with vascular surrounding cells non-reactive to a-SMA in PGs and PGCGs were $3.81 \pm 2.228$ and $10.53 \pm 3.432$, respectively. Statistical analysis showed a highly significant differences present between them $(P<0.01)$.

Conclusion The mean number of CD34 positive microvessels in PGs was significantly more than that of PGCG, but the mean number of vascular surrounding cells non-reactive to a-SMA was significantly less. This can add insight to the clinical behavior and might reflect the differences in pathogenesis of these lesions.

Keywords pyogenic granuloma, peripheral giant cell granuloma, CD34, a-SMA
\end{abstract}

\section{Introduction}

Oral mucosa is constantly exposed to external and internal stimuli and therefore manifests as a spectrum of diseases ranging from developmental, reactive, and inflammatory to neoplastic. ${ }^{1}$ Localized gingival reactive hyperplastic lesions are classified into four sub-types like pyogenic granuloma (PG), peripheral giant cell granuloma (PGCG), focal fibrous hyperplasia, and peripheral ossifying fibroma. ${ }^{2}$ Reactive lesions are non-neoplastic clinically and histologically and nearly they are clinically similar but possess distinct histopathological features. ${ }^{3}$

In general, $\mathrm{PG}$ is a common localized hyperplastic benign vascular lesion of the oral cavity, manifested as exophytic, sessile, erythematous, and painful nodule that is prone to bleeding and ulceration. ${ }^{4}$ Three quarters of all oral PGs occur on the gingiva, and most of them are in response to gingival inflammation and chronic gingival irritants. ${ }^{5-7}$

Peripheral giant cell granuloma is a painless, soft, reddish-bluish tumor-like reactive lesion, clinically bears resemblance to $P G,{ }^{8}$ however, it has significantly higher rate of recurrence than other reactive lesions and thus has to be treated with caution with complete excision and clearing of the lesion. ${ }^{9}$

Hematopoietic progenitor cell antigen CD34 also known as CD34 antigen is a protein that in humans is encoded by the CD34 gene. The CD34 protein is a member of a family of single-pass transmembrane sialomucin proteins that show expression on early hematopoietic and vascular-associated tissue. ${ }^{10} \mathrm{CD} 34$ is a surface glycophosphoprotein expressed on developmentally early hematopoietic stem and progenitor cells, small-vessel endothelia and embryonic fibroblasts. ${ }^{10}$
Myofibroblasts are metabolically and morphologically distinctive fibroblasts expressing alpha smooth muscle actin ( $\alpha$-SMA), and their activation plays a key role in development of the fibrotic response. ${ }^{11,12}$ They are involved in morphogenesis, inflammation, fibrosis and oncogenesis in many tissues and organs. Myofibroblasts help in extracellular matrix reorganization by the production of numerous inflammatory mediators, growth factors and proteins of the extracellular matrix. ${ }^{13}$ Transdifferentiation of fibroblasts into myofibroblasts is an early event in tumorigenesis and it is mediated by cytokines and growth factors which are expressed by tumor cells. $^{14}$

The pathogenesis of PG and PGCG remains to be not fully understood. In such conditions, immunohistochemistry may provide some practical help and shed a light on the underlying pathogenesis of these lesions. The aim of this research was to study the immunohistochemical expressions of CD34 and a-SMA for gingival pyogenic granuloma in comparison with peripheral giant cell granuloma. In such conditions, the immunohistochemistry may provide some practical help and shed a light on the underlying pathogenesis of these lesions.

\section{Materials and Methods}

The materials used in this study were consisting of 48 formalin fixed, paraffin-embedded biopsy specimens of gingival PG and 39 formalin fixed, paraffin-embedded biopsy specimens of PGCG. They were retrieved from the archives of Rizgary Teaching Hospital, Erbil (Ministry of Health, Kurdistan Region of Iraq) in the period between January, 2013 and 
August, 2016. Ten control gingival samples were obtained from clinically healthy patients undergoing orthodontic extractions in Erbil Specialized Dental Center. The written consent to carry out biopsies which were required for the study was obtained from healthy volunteers, after the necessary instructions.

Demographic data and clinical aspects were registered in a special form, and only patients with biopsy proven gingival PG or PGCG were included. The pregnant and edentulous patients (epulis fissuratum) and patients with known systemic disorders such as diabetes and bleeding disorders were excluded from the study. Sample collection was authorized by Rizgary Teaching Hospital, Ministry of Health. The research project was approved by the Research Ethics Committee at College of Dentistry, Hawler Medical University under protocol.

NovoLink $^{\mathrm{Tw}}$ Polymer Detection System codes RE7140-K from Leica Microsystems (UK) which includes Monoclonal Mouse Anti-Human CD34 (Clone QBEND/10, dilution 1:100), and an anti- $\alpha$-SMA Monoclonal Antibody (clone 1A4, diluted 1:100; Dako Corporation, Carpinteria, USA) were used. The staining procedure and the instructions included with each detection system were followed.

After necessary data had been collected, the results were given as mean \pm standard deviation. The potential difference among groups for histopathological data was evaluated using ANOVA test. All statistical calculations were done using computer programs Statistical Package for the Social Science (SPSS Inc., version 19). Statistical significance of differences between the groups was tested with the Mann-Whitney $U$ test. $P$-value $\leq 0.05$ was considered statistically significant.

\section{Results}

The samples used in this study consist of 48 cases of histologically proven PGs and 39 cases of histologically proven PGCGs. The age and sex distribution for both cases are seen in Fig. 1.
The maxilla was mostly affected by PG (66.7\%), followed by the mandible (33.3\%), 39.6\% cases showed a maximum diameter $<1.5 \mathrm{~cm}, 52.1 \%$ showed a maximum diameter $1.5-3 \mathrm{~cm}$, and only $8.3 \%$ showed a maximum diameter $>3 \mathrm{~cm}$.

The results also showed that the mandible was mostly affected by PGCG (72.4\%), followed by the maxilla (27.6\%). About $39.9 \%$ cases showed a maximum diameter $<1.5 \mathrm{~cm}$, $48.7 \%$ showed a maximum diameter of $1.5-3 \mathrm{~cm}$, and only $15.4 \%$ showed a maximum diameter $>3 \mathrm{~cm}$.

\section{Histopathological Pictures}

Hematoxylin and eosin results

The pyogenic granuloma revealed hyperplastic keratinized stratified squamous epithelium with some areas of epithelial atrophy or ulcerations. The most important features are the occurrence of large numbers of endothelium-lined vascular spaces and the extreme proliferation of fibroblasts cells and inflammatory cells (Fig. 2).

Microscopic examination of the sections of PGCG showed the presence of hyperplastic keratinized stratified squamous epithelium, and the overlying mucosal surface was ulcerated in some areas. Histopathologically, fibroblasts in the stroma form a basic element of the lesion and are plump oval to spindle-shaped. Multi-nucleated giant cells of variable shapes and sizes and containing multiple nuclei were seen scattered throughout the connective tissue stroma (Fig. 3). The connective tissue stroma also reveals some vascularity with different types of inflammatory cell infiltration, and foci of hemorrhage were also observed.

\section{Immunohistochemical results}

The number of CD34 positive microvessels was considered as a MVD. Any brown staining of endothelial cells or cluster of endothelial cells with or without a lumen that is clearly separate from adjacent microvessels and other connective tissue elements is considered as a single vessel. Branching structure

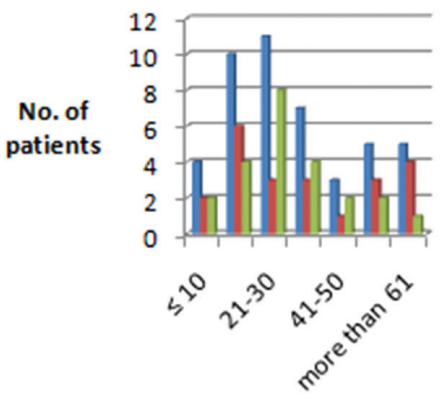

Age group

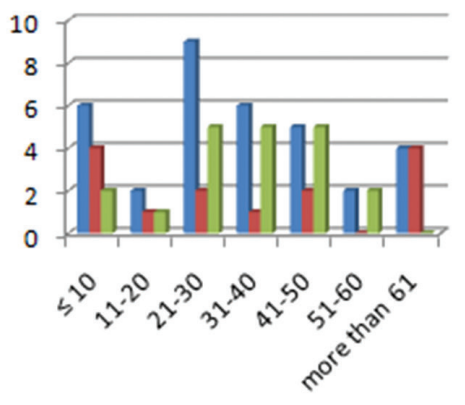

Age group
No. of patients

\section{Male}

armale

Fig. 1 Age and sex distribution of (A) pyogenic granuloma and (B) peripheral giant cell granuloma.
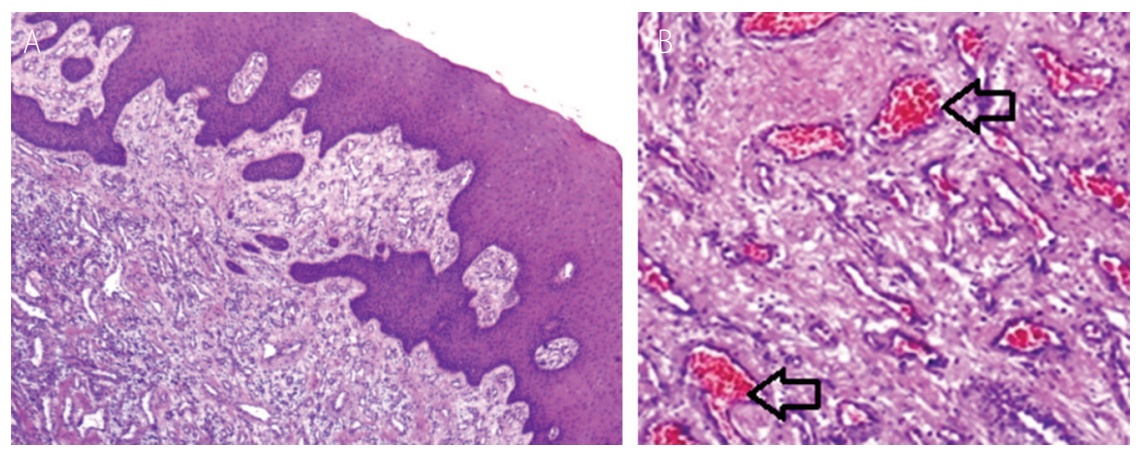

Fig. 2 Photomicrograph ofpyogenic granuloma with hyperplastic epithelium that overlies a connective tissue that contains numerous inflammatory cells and blood vessels (A1: H\&E 100X). Fibrod vascular connective tissue consisting of numerous endothelium-lined vascular spaces engorged with red blood cells (arrows), and numerous fibroblasts infiltrated with inflammatory cells (A2: H\&E 400X) 
was counted as a single vessel unless there was a break in the continuity of the structure. All samples used in the study demonstrated positive reaction for CD34 (Figs. 4 and 5). The MVD for PG and PGCG was ranging (7.7-63.9) and (6.946.4) respectively.

Statistical analysis of the MVD for PG showed no significant relation with the gender, site and the maximum diameter of the lesions. Statistical analysis of MVD for PGCG showed significant relation $(P<0.05)$ with the gender, but a non-significant relations present with the site and the maximum diameter of the lesions $(P>0.05)$ as seen in Table 1.

The mean number of the CD34 positive microvessels in PGs, PGCGs, and normal gingiva was $32.58 \pm, 17.778$ $11.208 \pm 22.4$, and $1.197 \pm 8.21$, respectively. Statistical analysis showed a highly significant difference present between PG and normal gingiva, PG and PGCG, PGCG and normal gingiva regarding the MVD $(P<0.01)$ as seen in Table 2.

In this study, a-SMA - positive stromal cells and vascular surrounding spindle cells that showing brown cytoplasmic immunostaining, were considered to be myofibroblasts. Vascular surrounding cells and other stromal mesenchymal cells in all samples of normal gingiva revealed immune negativity to
a-SMA. Some of the vascular surrounding cells in PGs and PGCGs studied revealed immune positivity to a-SMA especially in PG, but the other stromal mesenchymal cells were negative in both PG and PGCG.

The number of blood vessels with vascular surrounding cells non-reactive to a-SMA was counted. In PG, the number of non-reactive blood vessels was ranging 1.3-9.4. While in PGCG the number of non-reactive blood vessels was ranging 4.8-18.2. Statistical analysis for PG and PGCG showed no significant relation with the gender, site and the diameter of the lesions $(P>0.05)$ as seen in Table 3 .

The mean number of blood vessels with vascular surrounding cells non-reactive to $\alpha$-SMA in PG was $3.81 \pm 2.228$, but in PGCG, it was $10.53 \pm 3.432$. Statistical analysis showed a highly significant differences present between PG and PGCG regarding the number of blood vessels with vascular surrounding cells non-reactive to $\alpha$-SMA $(P<0.01)$ as seen in Table 4.

\section{Discussion}

Pyogenic granuloma and peripheral giant cell granuloma are common lesions of oral cavity. The pathogenesis remains to be
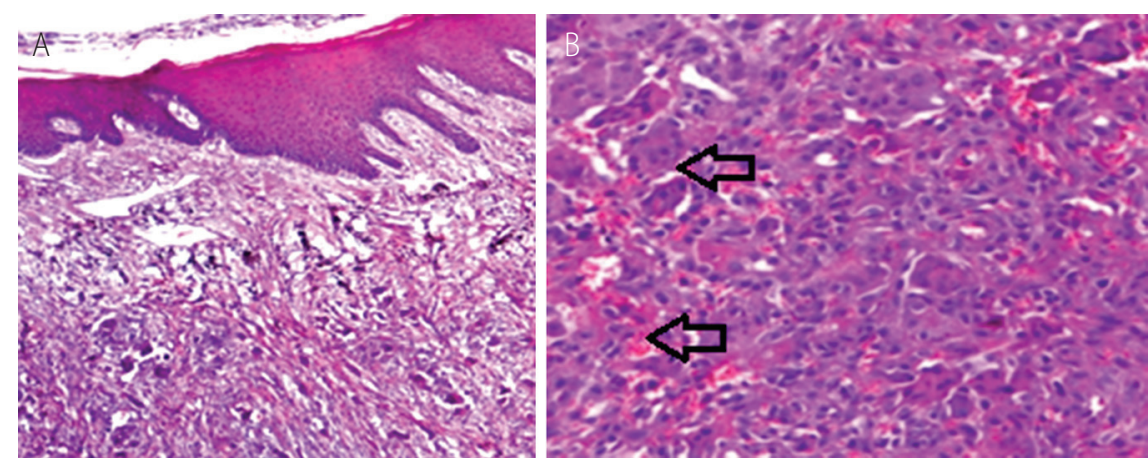

Fig. 3 Photomicrograph of peripheral giant cell granuloma, revealed hyperplastic epithelium that overlies vascular connective tissue which contain numerous multinucleated giant cells (A1: H\&E 100X). Abundant multinuclen ated giant cells (upper arrow) together with inflammatory cell infiltration and areas of hemorrhage (lower arrow) are also seen (A2: H\&E 400X).
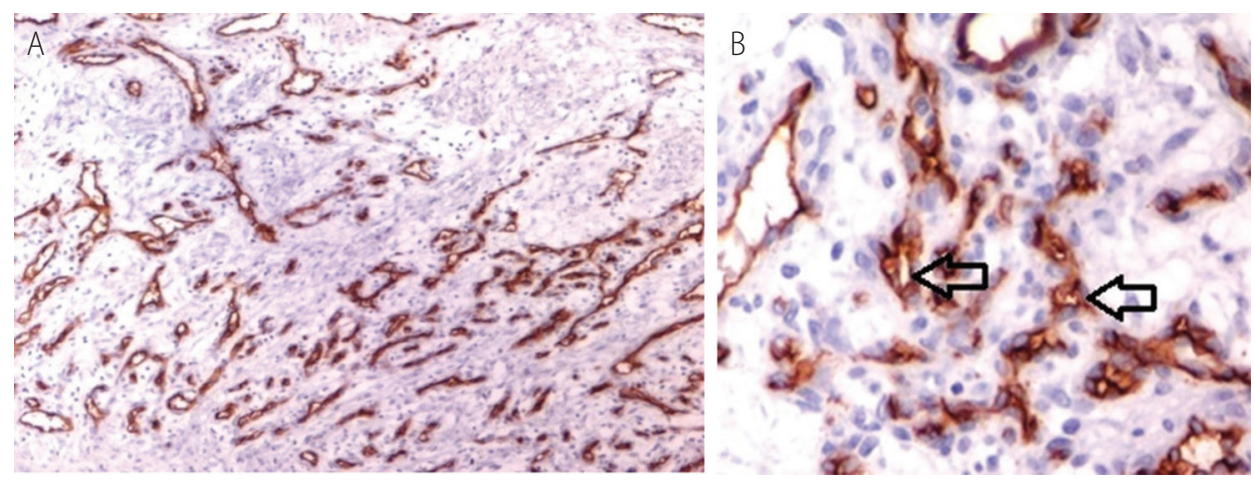

Fig. 4 Photomicrographs revealed the microvessels expressed by CD34 marker in the pyogenic granuloma (arrows) (A1: Immunohistochemistry 100x; A2: Immunohistochemistry $400 \times)$.
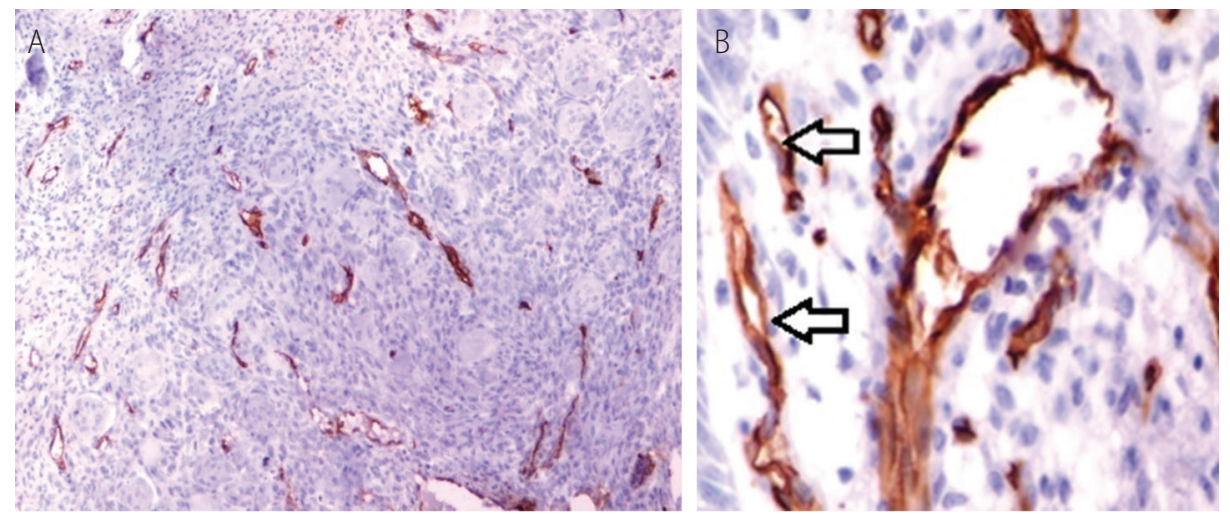

Fig. 5 Photomicrographs revealed the microvessels expressed by CD34 marker in the peripheral giant cell granuloma (arrows) (A1: Immunohistochemistry 100x; A2: Immunohistochemistry 400X). 


\begin{tabular}{|c|c|c|c|c|c|}
\hline \multirow{2}{*}{\multicolumn{2}{|c|}{$\begin{array}{l}\text { Table 1. Distribution } \\
\text { of microvessel density } \\
\text { the maximum diamet } \\
\text { giant cell granuloma } \\
\text { Clinical parameter }\end{array}$}} & \multicolumn{2}{|c|}{ PG } & \multicolumn{2}{|c|}{ PGCG } \\
\hline & & $X \pm S D$ & $P$-value & $X \pm S D$ & $P$-value \\
\hline \multirow{3}{*}{ Gender } & Male & $\begin{array}{c}26.79 \pm \\
15.97\end{array}$ & 0.091 & $\begin{array}{c}18.56 \pm \\
12.047\end{array}$ & 0.03 \\
\hline & \multirow[t]{2}{*}{ Female } & \multirow{2}{*}{$\begin{array}{c}37.06 \pm \\
18.154\end{array}$} & $>0.05$ & \multirow{2}{*}{$\begin{array}{c}25.06 \pm \\
9.994\end{array}$} & $<0.05$ \\
\hline & & & NS & & S \\
\hline \multirow{3}{*}{ Site } & Maxilla & $\begin{array}{c}30.52 \pm \\
16.964\end{array}$ & 0.852 & $\begin{array}{l}25.5 \pm \\
12.074\end{array}$ & 0.379 \\
\hline & \multirow[t]{2}{*}{ Mandible } & \multirow{2}{*}{$\begin{array}{c}31.27 \pm \\
19.216\end{array}$} & $>0.05$ & \multirow{2}{*}{$\begin{array}{c}22.01 \pm \\
11.806\end{array}$} & $>0.05$ \\
\hline & & & NS & & NS \\
\hline \multirow{3}{*}{$\begin{array}{l}\text { Maximum } \\
\text { diameter } \\
(\mathrm{cm})\end{array}$} & $<1.5$ & $\begin{array}{c}35.44 \pm \\
18.363\end{array}$ & 0.591 & $\begin{array}{c}18.23 \pm \\
9.807\end{array}$ & 0.131 \\
\hline & $1.5-3$ & $\begin{array}{c}30.82 \pm \\
17.15\end{array}$ & $>0.05$ & $\begin{array}{c}24.22 \pm \\
11.727\end{array}$ & $>0.05$ \\
\hline & $>3$ & $\begin{array}{l}27.3 \pm \\
21.463\end{array}$ & NS & $\begin{array}{c}26.35 \pm \\
11.39\end{array}$ & NS \\
\hline
\end{tabular}

PG: pyogenic granuloma, PGCG: peripheral giant cell granuloma, $X$ : mean, SD: standard deviation, cm: centimeter, NS: non-significant, S: significant.

\begin{tabular}{|c|c|c|c|c|}
\hline $\begin{array}{l}\text { CD34 } \\
\text { (MVD) }\end{array}$ & $\begin{array}{c}\text { No. } \\
\text { (Negative) }\end{array}$ & $\begin{array}{c}\text { No. } \\
\text { (Positive) }\end{array}$ & $X \pm S D$ & $P$-value \\
\hline \multirow{5}{*}{ PG } & \multirow{5}{*}{0} & \multirow{4}{*}{48} & \multirow{4}{*}{$\begin{array}{l}32.58 \pm \\
17.778\end{array}$} & 0.0001 \\
\hline & & & & ${ }^{*}<0.01$ \\
\hline & & & & HS \\
\hline & & & & 0.0001 \\
\hline & & & & ${ }^{* *}<0.01$ \\
\hline \multirow[t]{2}{*}{ PGCG } & \multirow[t]{2}{*}{0} & \multirow[t]{2}{*}{39} & \multirow{2}{*}{$\begin{array}{l}22.4 \pm \\
11.208\end{array}$} & HS \\
\hline & & & & 0.0001 \\
\hline \multirow{2}{*}{$\begin{array}{l}\text { Normal } \\
\text { gingiva }\end{array}$} & \multirow[t]{2}{*}{0} & \multirow[t]{2}{*}{10} & \multirow[t]{2}{*}{$8.21 \pm 1.197$} & ${ }^{* * * *}<0.01$ \\
\hline & & & & HS \\
\hline
\end{tabular}

"Comparison between PG and normal gingiva. "*Comparison between PG and PGCG. ${ }^{* * *}$ Comparison between PGCG and normal gingiva. X: mean, SD: standard deviation, No: number, HS: highly significant.

\begin{tabular}{|c|c|c|c|c|c|}
\hline \multirow{2}{*}{\multicolumn{2}{|c|}{$\begin{array}{l}\text { Table 3. Distribution } \\
\text { the number of blood } \\
\text { non-reactive to a-SM } \\
\text { the maximum diame } \\
\text { giant cell granuloma } \\
\text { Clinical parameter }\end{array}$}} & \multicolumn{2}{|l|}{ PG } & \multicolumn{2}{|c|}{ PGCG } \\
\hline & & $X \pm S D$ & $P$-value & $X \pm S D$ & $P$-value \\
\hline \multirow{3}{*}{ Gender } & Male & $3.90 \pm 1.973$ & 0.548 & $11.43 \pm 3.614$ & 0.241 \\
\hline & Female & $4.73 \pm 2.458$ & $>0.05$ & $9.91 \pm 3.232$ & $>0.05$ \\
\hline & & & NS & & NS \\
\hline \multirow{3}{*}{ Site } & Maxilla & $3.94 \pm 2.208$ & 0.892 & $10 \pm 3.338$ & 0.558 \\
\hline & Mandible & $3.77 \pm 2.538$ & $>0.05$ & $10.85 \pm 3.26$ & $>0.05$ \\
\hline & & & NS & & NS \\
\hline
\end{tabular}

\begin{tabular}{lccccc} 
& & & & \multicolumn{3}{r}{ Continued } \\
\hline Maximum & $<1.5$ & $3.73 \pm 1.995$ & 0.119 & $10.92 \pm 3.709$ & 0.143 \\
diameter & $1.5-3$ & $4.4 \pm 2.415$ & $>0.05$ & $11.05 \pm 2.837$ & $>0.05$ \\
$(\mathrm{~cm})$ & $>3$ & $2 \pm 0.816$ & NS & $8 \pm 3.949$ & NS \\
\hline
\end{tabular}

PG: pyogenic granuloma, PGCG: peripheral giant cell granuloma, $X$ : mean, SD: standard deviation, cm: centimeter, NS: non-significant.

Table 4. The relations between the pyogenic granuloma and peripheral giant cell granuloma for $a-S M A$.

\begin{tabular}{lccll}
\hline $\boldsymbol{a}-S M A$ & No. (Negative) & No. (Positive) & $\mathbf{X} \pm$ SD & P-value \\
\hline PG & 0 & 48 & $3.81 \pm 2.228$ & 0.0001 \\
& & & & \\
PGCG & 0 & 39 & $10.53 \pm 3.432$ & $\begin{array}{l}* \\
\text { HS }\end{array}$ \\
& & & & HS.0001
\end{tabular}

"Comparison between PG and PGCG. X: mean, SD: standard deviation, No: number, HS: highly significant.

not fully understood. In such conditions, immunohistochemistry may provide some practical help and shed a light on the underlying pathogenesis of these lesions.

\section{CD34 Immunostaining Distribution}

In this study, the mean value of MVD of normal gingiva specimens was $8.21 \pm 1.197$. Our results were nearly similar to Seyedmajidi et al.'s ${ }^{15}$ result; they found the MVD of all samples of healthy gingiva was $7.95 \pm 5.56$. The mean value of MVD of samples of PGs was $32.58 \pm 17.778$. Our results were less than Vasconcelos et al.'s ${ }^{16}$ result which was $48.09 \pm 30.031$, but more than that of Seyedmajidi et al.'s ${ }^{15}$ which was $20.01 \pm 11.88$. The increased expression of CD34 can be attributed to the increase in the number of blood vessels in pyogenic granuloma and appears to be involved in pathogenesis of oral pyogenic granuloma. ${ }^{15}$

The mean number of MVD of samples of PGCG was 22.4 \pm 11.208. Our results were less than Hallikeri et al.s ${ }^{17}$ result which was $30.05 \pm 8.006$. The higher expression of CD34 biomarkers in $\mathrm{PG}$ as a vessel-rich lesion compared with normal gingiva and PGCG, illustrates the role of these molecules as angiogenesis related markers. The variation of mean MVD among the groups suggests that angiogenesis may be one of the mechanisms possibly contributing to the different biological behavior, architecture or pattern of growth, and may be an important step for the study of new therapy. ${ }^{15}$

\section{Alpha-smooth Muscle Actin Immunostaining Distribution}

The most frequently used myofibroblast marker is $\alpha$-SMA. ${ }^{18}$ The number of blood vessels with vascular surrounding cells non-reactive to a-SMA in PG was significantly less than that of PGCG. Most of the small, large blood vessels and abnormal blood vessels and spaces in PG had two or more outer layers of mesenchymal cells (myofibroblast) positive for a-SMA. The pattern of the distribution of these mononuclear myofibroblastic cells suggested that these cells might play a role in generating of newly formed blood vessels and spaces, since PG has more blood vessels in comparison with PGCG. Epivatianos ${ }^{19}$ and Kawachi ${ }^{20}$ also found that most perivascular spindle cells in PGs studied were strongly stained to a-SMA. 
The stromal mesenchymal cells between the blood vessels showed no reactivity to $\alpha$-SMA. Despite the similarity of PG to granulation tissue, we did not detect any stromal myofibroblasts in all samples of PG. Our results come in agreement with Damasceno et al., ${ }^{12}$ they did not noticed any stromal myofibroblast in PG.

Regarding the PGCG, this study showed that stromal spindle cells which morphologically resemble myofibroblasts were negative for $\alpha$-SMA, this result agree with that of Damasceno et al.s's ${ }^{12}$ study, but disagree with Filioreanu et al. ${ }^{21}$ and $\mathrm{Kujan}^{22}$ studies, they found that smooth muscle specific actin was strongly stained in the spindle mononuclear cells (myofibroblasts) distributed through the lesion.

The sub-classification of blood vessels into immature, intermediate and mature is required as this important using the combination of immunohistochemistry of CD34 and a-SMA stain to demonstrate pericyte. ${ }^{17}$ This is required to differentiate the intermediate blood vessels from the mature blood vessels. Since immature and intermediate blood vessels are considered as an indicator of the degree of angiogenic activity, and are the main target of anti-angiogenic therapy and not the mature blood vessels, quantification of immature blood vessels may be helpful in estimation of prognosis especially for agents that do selectively target angiogenic endothelial cells, information may provide additional evidence of therapeutic anti-vascular effect for the control and prevention of the growth by inhibition of angiogenesis by antiangiogenic therapy could be a potent therapeutic strategy.

\section{Conclusion}

Pyogenic granuloma showed more microvessel density and lesser number of blood vessels with vascular surrounding cells non-reactive to a-SMA were seen. This can add insight to the clinical behavior and might reflect the differences in pathogenesis of these lesions.

\section{Conflicts of Interest}

None.

\section{REFERENCES}

1. Neville BW, Damm DD, Allen CM, Bouquot JE. Oral and Maxillofacial Pathology. $2^{\text {nd }}$ Ed., 2005, pp. 371-372.

2. Reddy V, Saxena S, Saxena S, Reddy M. Reactive hyperplastic lesions of the oral cavity: a ten year observational study on north Indian population. J Clin Exp Dent. 2012;4:e136-e140.

3. Kamal R, Dahiya P, Puri A. Oral pyogenic granuloma: various concepts of etiopathogenesis. J Oral Maxillofac Pathol. 2012;16:79-81.

4. Saghafi S, Amoueian S, Montazer M, Bostan R. Assessment of VEGF, CD-31 and Ki-67 immunohistochemical markers in oral pyogenic granuloma: a comparison with hemangioma and inflammatory gingivitis. Iran J Basic Med Sci. 2011;14:185-189.

5. Jafarzadeh H, Sanatkhani M, Mohtasham N. Oral pyogenic granuloma: a review. J Oral Sci. 2006:48:167-175.

6. Gomes SR, Shakir QJ, Thaker PV, Tavadia JK. Pyogenic granuloma of the gingival: a misnomer? - A case report and review of literature. J Indian Soc Periodontol. 2013;17: 514-519.

7. Sharma A, Mathur VP, Sardana D. Effective management of a pregnancy tumour using a soft tissue diode laser: a case Report. Laser Ther. 2014;23:279-282.

8. Ramu S, Rodrigues CH. Reactive hyperplastic lesions of the gingiva: a retrospective study of 260 cases. World J Dent. 2012;3:126-130.

9. Motamedi MH, Eshghyar N, Jafari SM, Lassemi E, Navi F, Abbas FM, et al. Peripheral and central giant cell granulomas of the jaws: a demographic study. Oral Surg Oral Med Oral Pathol Oral Radiol Endod. 2007;103:e39-e43.

10. Gold M, Blanchet M-R, Samayawardhena LA, Bennett J, Maltby S, Pallen CJ, et al. CD34 function in intracellular signaling and mucosal inflammatory disease development. Allergy Asthma Clin Immunol. 2010;6:P15.

11. Cherng SH, Young J, Ma H. Alpha-smooth muscle actin (a-SMA). J Am Sci. 2008:4:7-9.

12. Damasceno LS, Gonçalves Fda S, Costa e Silva E, Zenóbio EG, Souza PE, Horta MC. Stromal myofibroblasts in focal reactive overgrowths of the gingiva. Braz Oral Res. 2012;26:373-377

13. Rao K B, Malathi N, Narashiman S, Trajan SH. Evaluation of myofibroblasts by expression of alpha smooth muscle actin: a marker in fibrosis, dysplasia and carcinoma. J Clin Diagn Res. 2014;8:ZC14-ZC17.
14. Amatangelo MD, Bassi DE, Klein-Szanto AJ, Cukierman E. Stromaderived three-dimensional matrices are necessary and sufficient to promote desmoplastic differentiation of normal fibroblasts. Am J Pathol. 2005; 167:475-488.

15. Seyedmajidi M, Shafaee S, Hashemipour G, Bijani A, Ehsani H. Immunohistochemical evaluation of angiogenesis related markers in pyogenic granuloma of gingiva. Asian Pac J Cancer Prev. 2015;16: 7513-7516.

16. Vasconcelos MG, Alves PM, Vasconcelos RG, da Silveira ÉJD, Medeiros AMC, de Queiroz LMG. Expression of CD34 and CD105 as markers for angiogenesis in oral vascular malformations and pyogenic granulomas. Eur Arch Otorhinolaryngol. 2011;268:1213-1217.

17. Hallikeri K, Acharya S, Koneru A, Trivedi D. Evaluation of microvessel density in central and peripheral giant cell granulomas. J Adv Clin Res Insights. 2015:2:20-25.

18. Hinz B. Formation and function of the myofibroblast during tissue repair Invest Dermatol. 2007:127:526-537.

19. Epivatianos A, Antoniades D, Zaraboukas TH, Zairi E, Poulopoulos A, Kiziridou A, et al. Pyogenic granuloma of the oral cavity: comparative study of its clinicopathological and immunohistochemical features. Pathol Int. 2005:55:391-397.

20. Kawachi N. A comparative histological and immunohistochemically study of capillary hemangioma, pyogenic granuloma and cavernous hemangioma in oral region with special reference to vascular proliferation factors. Int J Oral Med Sci. 2011;9:241-251

21. Filioreanu AM, Popescu E, Cotrutz C, Cotrut CE. Immunohistochemical and transmission electron microscopy study regarding myofibroblasts in fibroinflammatory epulis and giant cell peripheral granuloma. Rom J Morphol Embryol. 2009;50:363-368.

22. Kujan O, Al-Shawaf AZ, Azzeghaiby S, AlManadille A, Aziz K, Raheel SA. Immunohistochemical comparison of p53, Ki-67, CD68, vimentin, a-smooth muscle actin and alpha-1-antichymotrypsin in oral peripheral and central giant cell granuloma. J Contemp Dent Pract. 2015;16:20-24. 